\title{
Same but different? Similarities and fundamental differences of informal social networks in China (Guanxi) and Korea (Yongo)
}

\author{
Sven Horak \& Markus Taube
}

\begin{abstract}
This research reports on the similarities and distinctive differences between informal social networks in China (Guanxi) and Korea (Yongo). Within an analytical framework derived from social capital and institutional theory, the structural forms and characteristics of both network forms are compared. Although we observe some similarities, surprisingly, the two networks show several fundamental differences. Both are society-spanning constructs, developed and maintained by reciprocal action that creates trust and trustworthiness, and serves as a major factor in network cohesion. Both networks are relatively closed or inaccessible to outsiders, with insiders able to connect other insiders to each other (i.e., internal bridging of structural holes). However, Guanxi can be characterized as being utilitarian (purpose-based), whereas Yongo in principle describes cause-based ties. Furthermore, Guanxi networks are somewhat accessible to outsiders and draw on a diverse base of ties; Yongo networks are predefined, partly by birth, and are hence homogeneous and highly exclusive. Guanxi networks can benefit from spillover effects through bridging different networks; Yongo networks often cannot, as there is antipathy, competition, and potentially hostility between certain types of networks. The results add knowledge to social network theory in general and in particular on informal social networks in East Asia.
\end{abstract}

Keywords Informal institutions, Informal networks, indigenous research, Guanxi, Yongo 


\section{Introduction}

Whereas research on Chinese informal social networks (Guanxi) builds on decades of domestic and international scholarly research, a similar informal institution in South Korea (hereinafter Korea), Yongo, has thus far received much less attention. Theory building on the influence and nature of informal social networks in East Asia has so far almost solely relied on Guanxi research. In consequence, it is often claimed that what is true for Guanxi must also be true or at least similar for other informal networks. For instance, one camp of management scholars claims that the influence of informal institutions declines as a country develops its economic and political institutions (Annen, 2003; Peng, Wang, \& Jiang, 2008). In a similar fashion, classical sociological literature proposes that the transition from a primitive community to a complex modern society is achieved through solidarity. In this development process, initially fragmented clan-like compounds dissolve in the face of the division of labor required in modern societies, and solidarity and cooperation based on contractual relationships replace reliance on kin or clan alone (Durkheim, 1933). Both lines of argument view informal relationships as disappearing over time. However, if so, why do Yongo networks still appear to be strong in Korea, despite the country being an advanced and industrialized economy with stable formal institutions? If the theory held true, informal networks should have disappeared in Korea by now. It is further claimed that in principle everyone can develop Guanxi-based ties as they are not necessarily predefined (Luo, 2000; Luo \& Yeh, 2012). As for Yongo, the sociological literature reports that it "naturally" exists as it is largely predefined; hence the establishment and development of Yongo is limited per se.

Based on Guanxi theory, it is often argued that informal networks have similar characteristics, especially in terms of their persistence and diminution over the course of institutional evolution. Comparative studies are scarce and no studies have yet taken a comparative approach in analyzing Guanxi and Yongo. This study answers the question: "What is the difference between Guanxi and Yongo, and how does it affect current knowledge about informal social networks in East Asia?" Whereas Guanxi has been studied intensively (Chen, Chen, \& Huang [2013] identify more than 200 articles published in a selection of referred journals between 1990 and 2010), much less is known about Yongo in the international business and management literature. In this study, we provide a first examination of how Yongo works in complex interpersonal transactions under conditions of environmental uncertainty (Williamson, 1996). 
To shed more light on the gaps and dissonance within theory, we pursue a comparative conceptual approach by comparing the antecedents of Guanxi and Yongo. Our research approach follows the "most similar systems design" (MSSD) method proposed by Przeworski and Teune (1970), within which similar research objects are compared to identify differences. Both countries, China and Korea, belong to the same region, East Asia; moreover, both countries belong to the same cultural sphere, Confucian Asia, as classified by the GLOBE study (House et al., 2004).

This study proceeds as follows. We start by making recourse to transaction cost theory (Williamson 1979, 1996) as the basic foundation of our study. Then we move on to models introduced by economic sociologists, particularly Granovetter (1973), on the nature of ties in social networks, as well as Burt (1995) and Coleman (1988) on the structure of social networks; these latter works we understand as being complementary, providing additional depth to transaction cost theory-based reasoning (Hennart, 2015). In the next step, we define our research object, Guanxi and Yongo, in light of these paradigms. Thereafter, based on institutional and social capital research, we establish an analytical framework by means of which we strive to analyze the features of Guanxi and Yongo networks. By referring to the relevant literature, matched to the analytical frame, we characterize the structure and nature of both network types. Furthermore, we report on the results of the analysis, point the reader toward the limitations of our approach, and propose avenues for future research. The conclusion summarizes the key findings of this research.

\section{Theoretical foundation}

Transaction cost economics has made a seminal contribution to the analysis of economic interaction in so far as it has brought economic theorizing back into a realm where it can communicate and establish synergies with neighboring disciplines such as political science, psychology, sociology, etc. By accepting certain features of real-life economic transacting and shedding some of the most restrictive assumptions of classical and neo-classical theorizing, transaction cost theory allows the analysis of economic interaction in terms of what it actually is: an exchange of economic goods, not between rational, material utilitymaximizing automatons, but rather between individuals whose actions are determined by the fact that they are only boundedly rational, might behave opportunistically, and-perhaps most importantly — are embedded in social structures, which shatters the idea that all 
economic activity is anonymous and the identity of counterparts to a transaction does not matter.

The key insight of transaction cost theory is that there is a range of different types of market transactions, which require different governance modes, i.e., institutional foundations (Macmeil, 1974, 1978; Williamson 1979). Williamson (1979) sets out to explain these variations using the concept of asset specificity, i.e., the degree to which (high vs. low) specific monitoring and sanctioning mechanisms are required for potential non-cooperative behavior. Informal networks monitor the opportunistic behavior of free riders more effectively and at lower cost than bureaucratic control (Burt, 2000). However, the underlying problem of non-cooperative behavior by transaction partners might also be analyzed in the framework of trust as evolving in formal and informal institutional arrangements, as well as (various types) of social networks. Economic theories concerning "clubs" and research by economic sociologists on informal social networks elaborate on this latter approach.

Buchanan (1965) and Sandler and Tschirhart (1997) draw attention to the fact that economic clubs can keep the variable costs of cooperative transactions low-once resources have been invested in the structural setup of a network (fixed costs) encompassing a noninfinite number of members. ${ }^{1}$ Informal coordination and conciliation, as well as informal peer pressure and collective punishment mechanisms, are then able to keep transaction costs at a comparatively low level in comparison to exchanges with club-external actors. As cooperative behavior and honoring contracts is a precondition for being able to engage in further, low-cost transactions with network members in the future, compliance with network rules becomes a self-enforcing mechanism, or put differently, a dominant strategy (Davis, 1995; Taube, 2013).

Past research has shown that informal ties between actors play a major role in the coordination of a variety of actions, social and economic alike. Nee (1998) proposes that informal ties, based on informal norms, serve to coordinate economic behavior and decision making, in many cases by skirting formal rules. Informal ties are a powerful social tool for controlling behavior by preventing opportunism and free-riding. Informally organized groups often serve the welfare of neighborhood communities (Lin, 1999) or help in finding work (de Graaf \& Flap, 1988; Granovetter, 1973, 1995; Lin, 1999; Marsden \& Gorman, 2001; Montgomery, 1991).

\footnotetext{
${ }^{1}$ Recent insights from psychology indicate that the limits for the maximum size of functioning networks are quite restrictive, with human beings able to retain no more than 500 people on average as general acquaintances and able to identify only a maximum of 1,500 faces by name. Active networks with a substantial degree of interaction are limited to no more than 150 people (Dunbar, 2014).
} 
The informal organization of economic interaction has been studied —inter alia—by differentiating between "structural embeddedness" and "relational embeddedness." The concept of "structural embeddedness" captures the notion of network strength, i.e., its resilience to opportunistic behavior. The greatest strength is understood to exist in closed networks, in which every member is directly connected with everyone else. This allows information on both norm-abiding and opportunistic behavior to travel fast, and without distortions caused by intermediation. As a result (positive and negative) reputation is established in a fast and reliable fashion, consensus on shared norms and values evolves comparatively quickly (Aoki, 2007), and mutual trust can be created and nurtured in an effective manner (Burt, 2000; Coleman, 1990).

The concept of "relational embeddedness," in comparison, takes issue with the different strengths of specific, dyadic ties and their respective value to individual subjects. Granovetter (1973) classifies ties according to the intimacy of relationships, emotional attachments, the degree of trust involved, reciprocity, and the time invested in maintaining informal ties. Whereas, according to Granovetter, social ties can be strong or weak, it is weak ties that are understood to be most valuable as they have a greater reach of information allocation to distant spheres of an informal social network compared to strong ties. Weak ties are furthermore said to fulfill a bridging function (Coleman, 1988) of unconnected networks (overcoming "structural holes," in the terminology of Burt [1995]) by means of a wellconnected agent filling a node; this agent benefits through informational advantage and by sharing this advantage with other network members. Firms will do well in terms of benefitting from information when they can draw on a mix of strong and weak ties (Burt, 2000). To managers, however, network diversity is important. The more informal ties a manager possesses with peers only, the more these reduce the value of informal ties (Burt, 1997). Hence, maintaining a mix of informal ties, with peers as well as non-peers, is assumed to be optimal.

Much of the classic research on social networks has only explicitly considered the cultural environment (context) in which networks are embedded to a lesser extent. Several scholars have stressed the importance of contextualization in research conducted on Asia (Adler, Doktor, \& Redding, 1986; Dowling \& Donnelly, 2013). As social ties can be assumed to differ in nature and structure in individualistic and collectivistic cultures, for example, the nature and character of informal social networks can also be assumed to differ as a consequence. For instance, there is doubt concerning whether structural holes can be bridged 
in rather particularistic societies, in which there is a strong distinction between insider and outsider groups (Horak, 2014; Lee, 2000; Yee, 2000a; Yi \& Ellis, 2000).

We seek to contribute to social network theory by shifting the analytical level of inquiry from the macro level to the particular case of informal social networks in China and Korea, explicitly analyzing the indigenous nature and structure of both networks using a comparative approach.

\section{Defining Guanxi and Yongo}

Given the amount and intensity of Guanxi-related research, it is astonishing that the nature of other informal social networks prevalent in East Asia has been largely overlooked. East Asia is a region with many shared cultural traditions. For instance, China and Korea share the traditional notion of informal social networks: The generic terms for social networks, "renmai" in Chinese and "inmaek" in Korean, are both based on the same Chinese characters “人脉.” Whereas Guanxi is an established research stream in the international business and management literature, Yongo is currently surprisingly unknown. As China is a rising political and economic heavyweight, Guanxi is considered a central theme in gaining a better understanding of political and economic decision making in the country; in contrast, Yongo has so far been largely overlooked as an explanatory variable for Korea's rapid economic development and the competitive strength of global Korean industry leaders (Samsung, Hyundai, LG, etc.). Only recently have scholars proposed Yongo as an integral variable to explain Korea's economic rise (Lew, 2013) and underlined its importance in business (Horak, 2014).

\section{Guanxi}

There have been several different attempts to define Guanxi. Whereas earlier definitions of Guanxi appear to be rather broad in scope (Pye, 1982; Yang, 1994), recent explanations shed more light on its unique character (e.g., Li, 2007a, 2012b). Yang (1994) generally defines Guanxi as not only a social relationship, but a relationship between people, forces, and objectives. Pye (1982) uses the term friendship to define Guanxi, wherein the form of friendship is purpose-based with the intention of providing mutual support and is manifested through a continuous exchange of favors. The high importance of particular social ties was mentioned by Weber (1951), who observed that in "China no sense of obligation has existed toward impersonal communities, be they of political, ideological, or any other nature" (p. 
209). Fan (2002a, 2002b) describes Guanxi as a social relationship that is predominantly used instrumentally, one that delivers welfare and secured material, and addresses social needs to substitute for the inability of the state to do so (Xin \& Pearce, 1996). Guanxi implies an obligation to act reciprocally. Favors granted expect favors in return.

Guanxi can be defined as an informal institution (North, 1990; Peng, Pinkham, Sun, \& Chen, 2009; Scott, 2010) that is embedded in an environment comprised of rather weak formal institutions and strong informal social ties ( $\mathrm{Li}, 2007 \mathrm{~b}$ ). It is tempting to confuse Guanxi with social capital, a term developed out of Western thought (Bourdieu, 1986; Halpern, 2005; Portes, 1998; Putnam, 1995; Woolcock, 1998). It may not be the case that they are the same. According to Li, social capital "refers to a group-based social tie, either weakly instrumental or weakly sentimental, but largely depersonalized and primarily nonkinship-based" (2012b, p. 853). A "typical social tie in the West" and a "typical social tie in the East, Guanxi is a dyadic social tie, both sentimental and instrumental, strongly personalized, kinship- or non-kinship-based" (Li, 2012b, p. 853). The definition provided by Li stresses the dual nature of Guanxi (Li, 2007b), which is a multi-dimensional phenomenon. Based on the Western "either-or" (Ambler, 1994), it is rather difficult to understand, but natural from a Chinese perspective. The ability of Chinese thought to integrate what Western thought may tag as mutually exclusive positions is reflected and well described , for instance, in the Yin Yang concept (Chen, 2002; Fang, 2003, 2012; Faure \& Fang, 2008; Li, 1998). The paradox-solving approach that rests on the ancient indigenous Chinese philosophy of Yin Yang has its roots in Taoism, which provides the basis for an integrative holistic, dynamic, and dialectic view that $\mathrm{Li}(2008)$ defines as follows:

"Holistic duality" posits that a phenomenon or entity cannot be complete unless it has two opposite elements. (...) The tenet of "dynamic duality" posits that opposite elements will mutually transform into each other in a process of balancing under various conditions. (...) The tenet of "dialectical duality" posits that the holistic and dynamic tenets can stand because two contrary (relatively contradictory) yet interdependent (relatively compatible) elements exist as opposites in unity to mutually affirm (for consistency and equilibrium) and mutually negate (for completeness and punctuated shift). (...) The dialectical tenet is the most salient as the anchor for the other two tenets of duality. (p. 416) 


\section{Yongo}

According to Horak (2014), "Yongo is the term for personal relationships in Korea that are attached to affiliation to an informally organized group. (...) Yongo derives its main cohesion power from strong particularistic ties, based on kin, educational institution (school/university) and region" (p. 10). Whereas the yon in Yongo can be translated into "tie" in English, it includes the notion of a bond between individuals based on affection. The go implies that this bond exists for a reason, based on the same background of actors: this may include attending the same educational institution (at the same time or not) (in Korean: hakyon, 학연), family and blood ties (hyulyon, 혈 연), and ties based on the same hometown (jiyon, 지연). Each of these three tie bases, or the aggregate of all of them, forms a line of lifelong relationships. One distinct feature of Yongo is that two of its three tie bases are preset, predefined, given by birth. One is born into and belongs to a family with respective, more or less comprehensive, blood ties; one is born in a particular place, i.e., regional origin is set, and - the only exception that (today) is less predefined - one goes to a particular school or university. As for the latter, it has to be noted that originally hakyon referred solely to school (less to university) ties. As people used to go to school in the region where they were born, hakyon was originally quite strongly predefined. Today, it is not the school but rather the university that has become the decisive institution for determining individual careers and the early establishment of insider networks. Furthermore, high school graduates today are comparatively mobile in choosing a university away from their hometown; hence contemporary hakyon ties have become university-centered and less pre-determined than the former school-based hakyon ties, the latter today having been more or less merged with the concept of jiyon ties. However, irrespective of whether they are based on shared school or university experiences, hakyon ties are usually maintained for life. As in the case of other tie bases, graduates from schools and universities meet informally on a regular basis, sharing the costs of anniversary or wedding gifts or obituaries.

Yongo has existed for centuries. Indeed, Korean historians recorded Yongo-based factionalism during the Jeoson dynasty (ca. 1392-1910). In those days, the ruling Yangban class (aristocrats who promoted Confucian values as a societal and governance ideal) "grouped itself into mutually exclusive factions and clans that engaged in fierce rivalry. The fragmentation of the Yangban society along the line of scholarly association, kinship and region gave rise to purges and factional strife" (Sik, 2005, p. 84). Those three communities 
are exactly the base that defines Yongo as it still exists in Korea today, including a notion of rivalry and competition between groups.

Yongo is a relationship that naturally exists in Korea; it is immutable and irreversible. It is not purpose-based, but rather a conventional social relationship. Every Korean is a member of a Yongo network; there is no choice concerning whether to become a member or not as far as Yongo (hakyon, hyulyon, jiyon) is concerned. As people are quasi-born into Yongo networks, Yongo is sometimes perceived as a burden (Horak, 2014).

First, Yongo is a dyadic social tie; second, it opens up membership in a Yongo network consisting of people with whom one shares hakyon, hyulyon, and/or jiyon. The perception of as sometimes burdensome is due to the obligation Yongo carries with it. Let us consider an example: A works in company $\mathrm{X}$ and shares hakyon (i.e., a university-based tie) with B, who works in company Y. B needs a favor from A to help C, who works for company $\mathrm{Z}$ and does not know A personally. A has an obligation to help C (via B) due to hakyon. In addition, if B is much senior to A, A really cannot deny a favor requested by B as it would be highly unethical in a Yongo context. Although in this simplified example B is the one who occupies a central position and bridges ties within a network, Yongo networks are in principle decentralized, without no one person at the center of a network. Within a Yongo network, the behavioral norm is that everyone is obliged to cooperate and shares the commitment to do so.

As debated in reference to Guanxi (see Li, 2012b, above), an important question is whether Yongo can be classified as social capital. Yongo is a sentimental dyadic tie between people who share a common background. This tie is strongly personalized, emotional, and less instrumental. It is either kinship-based or non-kinship-based, in which latter case access to a Yongo network confers quasi-membership status within a pseudo-family, i.e., the Yongo network. As social capital is established based upon rather instrumental ties with less emotional affection between actors, network access being limited to largely predefined individual characteristics, Yongo, just as Guanxi, can hardly be regarded as conventional social capital. Thus, we suggest treating informal networks as a separate category.

\section{Antecedents of informal social networks}

In this section, we create an analytical frame based on which we compare Guanxi and Yongo. The purpose is to carve out typical structural elements and characteristic features of informal networks that define network characteristics and affect network cohesion. To do so, we focus on the classical social tie and social network literature, and its links to concepts in transaction cost theory by concentrating predominantly on the works of Granovetter (1985), Coleman 
(1988, 1990), Greif (1989), Putnam et al. (1993), Burt (1995, 2000), Ostrom and Ahn (2003), and $\mathrm{Li}$ (2007b). Given the multi-faceted literature on social networks, this specific focus and the parameters defined cannot provide a comprehensive picture, but should be understood as a first approximation in line with the research question.

As a fundamental definition, we understand informal networks to be the sum of informal social ties, whereas informality refers to "the nature of social ties and events as implicitly assumed, endogenously embraced, and flexibly enforced by peer pressures horizontally in a particularistic personalized process" (Li, 2007b, p. 229). These networks can be described as an aggregate of linkages or "a set of interconnected nodes" (Castells, 2001, p. 1).

A first and fundamental criterion for the structural set-up of a network is defined by the "network principle," i.e. its specific raison d'être as either a purpose-based or causebased institutional arrangement. Purpose-based networks are utilitarian in character and derive their capacity to persist over time first of all from their ability to create value for their participants in the present and the future. As such, they are usually comparatively flexible in their set-up and feature opportunistic traits with regard to the inclusion of "valuable" network members. In contrast, cause-based networks exist due to a shared heritage or joint experience in the past. They are not dependent on their ability to deliver utility in the future. As such, they are to a strong degree immutable and irreversible in character (Lew, 2013).

Networks are of different sizes. According to Bourdieu (1986), network size correlates with the endowment of social capital on which an actor within a network can - in principle_-draw. It might therefore be concluded that the larger a network, the more the potential benefits accessible to each actor (Annen, 2003). While this is true from a ceteris paribus perspective, it must be taken into account that benefits do not accrue automatically, as decisions are made by actors dependent on other actors influenced by the existing level of trust and the strength of ties (Bian, 2001; Faist, 2000; Li, 2007b). At the same time, it must be taken into account that increasing network size is accompanied by increasing transaction costs of information dissemination, coordination, and the enforcement of network discipline. Furthermore, the strength of ties will tend to diminish with an increasing number of network members as it becomes harder to uphold a given level of bilateral interaction intensity (Annen, 2003; Hennart, 2015). As a result, the social capital of a network of any size that is actually accessible, as well as its transaction cost endowment, is determined by its size - in 
conjunction with the specific manifestations of structural and relational embeddedness within a given network.

Moreover, networks differ according to the level of diversity of their members (Lew, 2013; Luo, 2000; Luo \& Yeh, 2012; Park \& Shin, 2005; Yee, 2000a), which can critically influence the emergence of closed networks in which everyone is connected to everyone else (structural embeddedness). At the level of relational embeddedness, the diversity of network members influences the strength of dyadic ties, and thus network cohesion. A high degree of homogeneity in networks may result from a self-enforcing process whereby both a high degree of network closure, with every member directly linked to every other member, and strong ties, which imply a high intensity of interaction between members, work together. In their entirety, they allow high efficiency in information transmission amongst network members, strengthened and more credible sanctioning capacity, and therefore stronger (i.e., more reliable) network discipline, transparent reputation mechanisms, and eventually the evolution of mutual trust and shared norms (Coleman, 1990; Jones et al., 1997).

Once established, shared norms support cooperation and back up trust, thereby contributing to lower transaction costs (North, 1990; Putnam, Leonardi, \& Nanetti, 1993). Values and norms of behavior are, however, also influenced by the cultural context from which they evolve (Fukuyama, 1995, 2002). Hence, to a great extent it is the environment—particularly the cultural context - that influences the openness of networks to outsiders. The closer the network and the more homogeneous its members in terms of norm understanding and adherence, the more efficiently networks function, but the more they forego potentially enriching impulses from external sources.

A further decisive differentiating structural feature of social networks lies in their capacity to bridge structural holes between members of a given network, as well as between networks as such (Burt, 1995; Coleman, 1988). This feature appears to be closely related to the specific manifestations of the tie base and the nature of ties in a given network (see below). A strong bridging capability may be understood to mobilize additional resources and make new specifications of social capital accessible. High bridging capacities may therefore strengthen the purpose-oriented capacities of a network from both the inter- and intranetwork perspectives. However, while intra-network bridging capacities may strengthen the cohesiveness (closure) of a given network and therefore provide structural strength, the impact of high inter-network bridging capacities on the internal stability of a given network in terms of network closure and tie strength might be negative. The latter effect results from 
the negative implications of increasing networks with regard to the capacity for information dissemination, tie strength, network homogeneity, etc. The net effects of all these impulses on the overall transaction cost endowment are inconclusive and depend on individual network patterns.

The high or low capacity of informal social networks to bridge holes between independent networks finds a limited substitute in their aptitude for accepting new members, who can introduce new resources to the network and increase its general social capital endowment. This openness of networks, which can range from highly opportunistic accessibility at one extreme to a state of full closure and non-negotiable exclusive membership at the other, is closely linked to the configuration of the social ties underlying a social network. Their design in terms of the underlying tie nature, tie base, and tie-based relation to outsiders is crucial for the overall functionality and transaction cost endowment of a given social network.

Networks differ in their openness and closedness, especially based on whether the value standard of their social ties, i.e. the tie nature, tends to be more particularistic or universalistic. Networks based on particularistic ties are in general rather closed and more difficult for outsiders to access. They tend to feature strong internal dyadic ties, and also promote ethnocentrism, fragmentation, and hostility toward other networks (Greif, 1989). Access to network-external resources, be it by bridging or the integration of new members, is therefore substantially restricted. At the same time, however, such networks can achieve high levels of relational and structural embeddedness, and thereby establish strong internal cohesion based on high trust. The high transaction costs (sometimes prohibitively high) of accessing external resources are mirrored by extremely low transaction costs of intra-network transacting.

Networks featuring more universalistic norms of behavior, and therefore less distinct from the network-external world, are more open to the inclusion of new members and benefit through their capacity to bridge networks. All this allows better access to external resources. However, the creation of a sense of identity and trust inside the network is more difficult, the cohesion of the network community vis-á-vis the external world is less pronounced, and the level of transaction cost of intra-network coordination (reliable information flows, upholding network discipline, etc.) tends to be higher.

These considerations directly relate to the notion of tie base, which can either be predefined according to a rigid set of "natural" characteristics, or more functional, with ties established based on specific considerations of functionality or utility and freed from 
"natural" characteristics, which cannot be influenced by individuals. Clearly, networks built on pre-defined tie bases have an inclination toward a particularistic tie nature and tend to feature a low degree of openness - and vice versa. As a consequence, the tie-based relation towards outsiders follows the same reasoning, with networks featuring pre-defined tie bases and particularistic tie nature tending to maintain a greater distance from outsiders and facing them to a greater degree in a competitive or even hostile manner.

A final distinguishing characteristic of social networks relates to their implementation of specific standards of reciprocity. The effect of reciprocity in economic transactions, a major universal norm of behavior in informal social networks, has been extensively researched (Fehr \& Falk, 1999; Kahneman, Knetsch, Thaler, \& Kahneman, 1986; Lee, 2007; Sugden, 1984). Reciprocal behavior is integral to establishing trust and trustworthiness (Akai \& Netzer, 2012; Bowles \& Gintis, 2002; Putnam, Leonardi, \& Nanetti, 1993; Song, Cadsby, \& Bi, 2012; Yamagishi, Jin, \& Kiyonari, 1999). These days, it is an accepted principle that reciprocal behavior is rewarded (positive reciprocity) and non-reciprocal behavior sanctioned (negative reciprocity) (Falk \& Fischbacher, 2000). Social capital scholars regard reciprocity as a precondition for voluntary cooperation. These norms occur through frequent recurring transactions and help to minimize opportunism and free riding. Reciprocity can be regarded as a social transaction process and an internalized norm at the same time (Coleman, 1988; Ostrom \& Ahn, 2003; Putnam, Leonardi, \& Nanetti, 1993).

Norms of reciprocity, whether markedly higher or lower, are a major factor determining cohesion in informal social networks. In general, it can be postulated that networks based on strong particularistic ties expect adherence to norms of reciprocity in the first place only from members of their own network, whereas expectations of reciprocity in more universalistic social tie systems are understood as also having validity outside the network. This difference has an effect on the transaction cost endowment of the respective social networks. The first type of network profits from a clear segregation of the external world and therefore comparatively transparent signals of network-internal norm compliance. This allows for a comparatively low level of transaction costs with regard to enforcing and upholding network discipline. As such, process-based trust can grow relatively quickly. All in all, this type of network features high static efficiency. In comparison, the latter type of network is burdened with lower transparency and therefore a higher level of transaction costs. Network discipline is more difficult to enforce and process-based trust harder to establish. At the same time, however, this type of network is better able to integrate external elements and 
adapt to new challenges arising from the outside world. As such, it features higher dynamic efficiency (Greif, 2006).

Figure 1 visualizes the structural and characteristic features of informal social networks discussed above. Furthermore, this framework serves as an analytic frame to compare Guanxi and Yongo.

Insert Figure 1 about here

\section{Comparison of Guanxi and Yongo}

Drawing on the framework established above, this section aims to provide a comparative characterization of Guanxi and Yongo. Each aspect is addressed in turn.

Network (principle, size, diversity). In principle, Guanxi is regarded as utilitarian and less sentimental than Yongo as the connection between people is based on a reciprocal exchange of favors (Fan, 2002a, 2002b; Luo, 2000). Hence, Guanxi tends to be purposebased. Yongo, on the contrary, is immutable and irreversible because it naturally exists between people, as described above. Hence, it is cause-based. With respect to the existence and development of trust in relational networks, this constellation results in marked differences. In the case of Guanxi, only very limited trust is offered at the beginning of a relationship (Lee, Pae, \& Wong, 2001). Strong personal trust must then develop over time, i.e., through the repeated mutual honoring of reciprocal transactions. In Guanxi networks, trust constitutes a dimension that can grow and shrink dynamically over time. Yongo networks, in comparison, feature a much higher level of basic trust, which is advanced to new members solely on the basis of specific natural attributes. As such, personal trust levels in Yongo networks start at a much higher level and develop much less dynamically over time. Variations in personal trust are then primarily determined by a) frequency of contact, b) multiplicity, and 3) duration of the relationship (Yee, 2015). Ultimately, however, our understanding of the different levels of trust remains an empirical issue that is yet to be determined.

The literature indicates that both Guanxi and Yongo networks can be regarded as sets of large networks together spanning the whole of society ( Huang, 2008; Lew, 2013; Yee, 2000a). While we examine the network level of Guanxi and Yongo in this study, it is important to understand the dyadic level of Guanxi from which networks evolve. The 
fundamental unit of Guanxi networks is the egocentric dyadic level, around which the network is built. Thus, a Guanxi network can range from small to large depending on the ability of the ego to bond with others (Chen \& Chen, 2004).

Popular categorizations of cultures as either individual- or group-based do not perfectly reflect the notion of Guanxi. Liang (1949) proposes a third category, relation-based, which constitutes a much better point of departure for understanding the nature of Guanxi. At a network level, Guanxi ties can be considered "the building blocks of Chinese society" (Huang, 2008, p. 469), whereby every Chinese person makes an effort to build and maintain Guanxi ties actively over the course of his or her life (Lin, 2001). At a rather general level, Yongo networks can be characterized in a similar way. Scholars describe them in the first place as relation-based, but emotional and characteristic of Korean society (Yee, 2000a), or they equate Korea with a "network society" (Kim, 2000). However, the Korean network society is regarded as fragmented into Yongo networks that draw on a narrow sense of family ties, education-based ties, and region-based ties, and leave less freedom for the active construction of heterogeneous network structures detached from hakyon, hyulyon, and jiyon. Hence, due to the members' backgrounds they tend to be "highly homogenous [sic]" (Park \& Shin, 2005) compared to Guanxi, which can be founded on larger and more diverse tie bases with ties that are in principle transferable.

Bridging function (between, within networks). Tie base is a critical factor in the distinction between Guanxi and Yongo. In terms of Yongo, there is no mixing between respective tie-based networks (i.e., hakyon, hyulyon, and jiyon) and there are no spillover effects. They tend rather to be in competition and can be hostile toward each other (Horak, 2014; Lee, 2000; Lew, 2013; Yee, 2000a). In other words, social networking is limited to one's own network, and even that differs compared to establishing social bonds from zero as Yongo is predefined, partly given by birth. Within the respective network, however, there is frequent exchange, ad-hoc trust ascription, cooperation, and friendship, framed in a familylike atmosphere. These sentimental and emotional notions within networks, in addition to the spillover effects or the bridging function within Yongo networks, are described in a similar fashion to Guanxi networks (e.g., Li, 2007a, 2007b). In sum, we see similarities when we compare within-Yongo ties to Guanxi ties.

Openness. In an extension to the prior discussion, although Guanxi has a certain base (e.g., friendship, kinship, co-workers, etc. [see Luo, 2000]), it is also "dynamic and certain social bases can be transferred" (Luo, 2000, p. 7). Whereas the cultivation, maintenance, and strengths of Guanxi ties require and are determined by reciprocity, commitment, affection, or 
sympathy, it can in principle be established among strangers through a third party in cases in which absolutely no bases exist. Hence, Guanxi networks can grow and are relatively open. Luo and Yeh (2012), for instance, argue that Guanxi networks, although dense, are to some extent quite open. Even foreigners can establish Guanxi. Yongo networks, in contrast, can only grow internally as the membership base is preset, i.e., they can intensify by expanding linkages to others from the same home town, high school, or university. It is usually not the case that a person from university A will have hakyon-based Yongo with someone from university B. Certainly both can have a trusting and close relationship, but this is by definition not Yongo. Nor can foreigners have Yongo as they possess no original Korean tie base. In comparison to Guanxi, Yongo is exclusive.

Social ties (base, nature, insider-outsider relations). The social base for establishing Guanxi is diverse. It can either be ascribed (e.g., family) or established through shared experiences (Li, 2007b; Luo, 2000). This, however, "facilitates the development of a Guanxi relation without predetermining it" (Luo, 2000, p. 4). A variety of bases can serve to establish Guanxi, e.g., regional origin, language/dialect, same surname, kinship, clan, co-workers, membership of associations, and clubs or friendship (Luo, 2000). What is relevant here is simply a perceived similarity (Lee, Pae, \& Wong, 2001). On the other hand, Yongo, as mentioned before, is predefined by hakyon, hyulyon, and jiyon. Hence, Yongo is strongly particularistic in a classic sense as it segregates people by nature.

However, viewing China's relation-based society from the perspective of the conventional (Western) dichotomy between universalism and particularism is somewhat inaccurate (Farh, Earley, \& Lin, 1997). In a society that is by nature relation-based, the art of establishing personalized ties is a universal procedure in which every member of society believes. From this point of view, in addition to the fact that, in principle, everyone can establish some form of Guanxi, it can be regarded as universal, independent of whether this stands in conflict with conventional Western thought (Chen \& Miller, 2010; Li, 2012a; Lin, 2002). As a consequence, outsiders who do not belong to a Guanxi network are treated as outsiders in a respectful way as they are potential future network members. Yongo also treats outsiders in an egalitarian way, but it is an egalitarianism of an entirely different sort. Within segregated Yongo networks, there is "flexibility, tolerance, mutual understanding as well as trust. Outside the boundary, on the contrary, people are treated as 'non-persons' and there can be discrimination and even hostility" (Kim, 2000, p. 179).

Reciprocity. Reciprocity is an integral factor in establishing Guanxi and is a determinant in intensifying predefined Yongo relationships. Both Guanxi- and Yongo-related 
literature points out the vital nature of reciprocal action for both forms of networks (Lew, 2013; Li, 2007b; Luo, 2000; Song, Cadsby, \& Bi, 2012; Yee, 2000a), as it produces trust and trustworthiness, which in turn constitute an efficient control mechanism of informal networks (Granovetter, 1985). Although we can claim that interpersonal trust exists in Guanxi as well as in Yongo networks in principle, determining the de facto strength of trust across the multiple layers in the two networks remains an issue to be addressed by empirical research. This is important to determine the extent to which reciprocity is expected, i.e., whether it is mandatory per se, or enforced to a lesser extent. We hypothesize that the generalized exchange rule routinely in force in Yongo networks (i.e., the rewards a person receives from others independent of the resources provided by that individual) more likely applies to individuals belonging to the inner circle of the network, in which trust may be most pronounced. However, empirical research is needed to shed more light on this process.

Insert Table 1 about here

To illustrate the actual impact of various manifestations of the 10 categories introduced here in relation to transactions conducted in Guanxi and Yongo networks, let us take a second look at the example of Yongo-based transactions introduced earlier. It should be noted that this is a stylized scenario based on the actual structural features and characteristics of Guanxi and Yongo networks (see Table 2).

Insert Table 2 about here

\section{Results}

As a result of our study, we find some similarities in the features of Guanxi and Yongo, such as network size, a bridging function within a network, and an obligation for reciprocal action (see Table 1, nos. 2, 5, and 10). More importantly, we find several fundamental differences, including purpose-based and cause-based ties, the diversity of network members, the ability to benefit from spillover effects to other networks (i.e., the bridging function between 
networks), accessibility (openness) toward new members, and several very different features that characterize social ties (tie base, nature, and behavior toward outsiders).

We see the most important difference in the fact that Guanxi relationships are transferable and can in principle be established between anyone, whereas Yongo relationships are predefined and virtually given by birth. This leads to a rather heterogeneous composition of Guanxi networks, unlike Yongo networks, which are strongly homogeneous.

We also contribute to the general theory of social networks (Coleman, 1988; Granovetter, 1985) by arguing that the benefits of spillover effects, i.e., the bridging function between networks of the same tie base (hakyon, hyulyon, jiyon), may not work for networks structured in the way that Yongo is. We also find general network theory to be rather incognizant of the distinctive features of the cultural context. First and foremost, in the case of Yongo, access to networks is largely predefined, i.e., skillful, competent, or well-connected members may be unable per se to connect to certain networks. Furthermore, competition, antipathy, and even hostility can exist between networks. Finally, Yee (2000a) points out the consistently strong family ties in Korean business: "Strong familial ties are more salient in instrumental usage, it is interpreted as the 'strength of strong ties"' (Yee, 2000a, p. 340). In the case of Korea, this study casts doubt on whether Granovetter's (1973) popular thesis on "the strength of weak ties" holds without considering the more dominant influence of strong and predefined ties. Surprisingly, all this ultimately seems to not be a barrier to progress, prosperity, or the development of a stable democracy, as the case of Korea shows. Informal networks do not hinder the establishing of stable formal institutions, nor do they hamper economic growth. Recently, Lew (2013) pointed toward the missing links in understanding the development of the Korean economy and put Yongo at the center of his research. More research in this direction is needed to gain a better understanding of the phenomenon and the unique nature of Yongo.

\section{Discussion}

The debate concerning whether informal social networks will persist in the long run or recede is currently ongoing in the international business and management literature. Two camps can be distinguished. One camp argues that informal networks are deeply ingrained within the respective cultural context and hence are culturally driven; thus, as culture is rather rigid and does not change fast (Hofstede, 2007), informal networks will likely persist (Anderson \& Lee, 2008; Yi \& Ellis, 2000). Other scholars argue that the more an economy develops and the more formal institutions stabilize, the less people will be inclined to use informal ties. 
Thus, informal networks are assumed to be institutionally driven (Annen, 2003; Peng, Wang, \& Jiang, 2008). A third camp of scholars, occupying middle ground, stress the dynamic nature of Guanxi today, assuming that "there is an emerging new form of Guanxi conduct that involves knowledge and information exchange" (Guo \& Miller, 2010, p. 287). Thus, it is likely that informal social networks are both culture-driven and institution-driven (Li, 1998, 2008, 2010). While several authors assume that Guanxi will probably disappear in the long run (Gu, Hung, \& Tse, 2008; Guthrie, 1998; Hutchings \& Weir, 2006; Peng, Wang, \& Jiang, 2008; Wilson \& Brennan, 2010), it should be noted that most research draws on studies only of Guanxi. However, it is doubtful whether we can speak of a general theory without taking the informal social networks of other countries into account.

Against the background of a sizeable body of literature discussing the potential persistence of informal social networks based on the study of Guanxi networks only, we therefore raise the call for greater differentiation. Pessimistic expectations concerning the future of Guanxi networks may not hold for the specific design of Yongo networks. Indeed, we see quite clear evidence in the literature that speaks of the persistence of Yongo networks. Yongo networks can be regarded first of all as culturally driven (and not so much institutionally driven) and this may explain the persistence of Yongo in an advanced economy today (Horak, 2014; Lee, 2000; Lew, 2013; Lew, Choi, \& Wang, 2011; Sik, 2005; Yee, 2000a). Furthermore, the continuing trend toward a higher degree of competition and a higher level of transparency appear to be inducing conventional types of Yongo-based transactions to adjust to modern times (Yee \& Chang, 2009). These arguments speak in favor of a rather dynamic character of Yongo and against its imminent demise.

Finally, it must be stressed that drawing general conclusions regarding the nature of informal social networks based solely on Guanxi or Yongo is insufficient. As this study has shown, the diverse structural features and characteristics exhibited by Chinese Guanxi networks and the Korean Yongo networks create different comparative advantages, which allow these networks to thrive and persist in different socio-economic environments. While this study contributes to the ongoing debate by explicitly considering Yongo as an important case for theory development, future research should take informal social networks of other countries into account to advance and contribute to this important debate. For instance, in working toward a theory applicable to the East Asian region, an extended focus could be achieved by including Japanese informal social ties in the debate. Although the distinctive features of Japanese culture have been studied for several decades, informal social networks have been discussed to a lesser extent (Gilbert, 2003; Suzuki, 1989) and have not been 
introduced in Guanxi-based theory building on informal social networks. This appears to constitute a substantial oversight as the Japanese term for informal social networks, "jin myaku," is based on the same Chinese characters of “人脉” that constitute the Chinese term "renmai" and the Korean "inmaek." As such, an in-depth analysis promises to shed light on the differences between all three types of network, important in informal and interpersonal transactions in their respective countries. This would add knowledge to transaction cost economics and extend the popular social capital debate by determining whether these networks can be regarded as social capital or make up a category of their own, which might develop into a whole new research agenda.

\section{Limitations}

This paper has aimed to provide an initial characterization of the similarities and fundamental differences between informal social networks in East Asia, focusing on Guanxi and Yongo. The analytical frame created to structure the analysis features the main characteristics of informal social networks. However, given the multi-faceted literature on this subject, we make no claims for the completeness of our model. When studying other phenomena, the basis for comparison may be structured differently. For instance, when studying political alliances and political struggles, the centralization of power in a network will be an important dimension. Furthermore, although key characteristics were derived from the literature, a conceptual approach cannot answer important empirical questions, such as how strong or weak tie strength in fact is between individuals, or how pronounced dyadic and group loyalty or trust are in both networks. We know from Guanxi research that the intensity of tie strengths, loyalty, and trust differs greatly (Li, 2007b; Luo, 2000). There is considerably less empirical evidence for Yongo as fewer studies have been undertaken so far in the field of international business and management studies. To establish a theory of informal social networks in East Asia not solely based on the study of Guanxi, future research should adopt comparative empirical approaches.

\section{Conclusion}

In conclusion, we propose taking a range of different characteristics of informal social networks into account to further theory development. Whereas some structural features seem to be similar between Guanxi and Yongo, we find several differences, such as the unlikeliness of bridging and spillover effects between Yongo networks of the same tie base, and the 
inaccessibility of networks for those who have a background incompatible with the homogeneous group of existing members as Yongo is predefined and partly given by birth compared to Guanxi. We contribute to the general theory of social networks by pointing to the cultural limits to establishing and developing ties in Yongo and propose, in the case of Korea, that the notion of the "strength of strong ties" (Yee, 2000, p. 340) is more realistic than the theory of weak ties, which are assumed to be more beneficial for coordinating activities (Granovetter, 1973). As differences in tie, trust, and loyalty strength can best be distinguished by pursuing comparative empirical work, we recommend that future research applies comparative methods to shed more light on the differences and similarities between informal social networks in East Asia, thereby complementing theory development on East Asian informal social networks. With this paper, we hope to provide a first impulse in this direction.

\section{References}

Adler, N. J., Doktor, R., \& Redding, S. G. 1986. From the Atlantic to the Pacific century: Cross-cultural management reviewed. Journal of Management, 12(2): 295-318.

Akai, K., \& Netzer, R. J. 2012. Trust and reciprocity among international groups: Experimental evidence from Austria and Japan. The Journal of Socio-Economics, 41(2): 266-276.

Ambler, T. 1994. Marketing's third paradigm: Guanxi. Business Strategy Review, 5(4): 6980.

Anderson, A. R., \& Lee, E. Y. 2008. From tradition to modern: Attitudes and applications of guanxi in Chinese entrepreneurship. Journal of Small Business and Enterprise Development, 15(4): 775-787.

Annen, K. 2003. Social capital, inclusive networks, and economic performance. Journal of Economic Behavior \& Organization, 50(4): 449-464.

Aoki, M. 2007. Endogenizing institutions and institutional changes. Journal of Institutional Economics, 3(1): 1-31.

Buchanan, J. M. 1965. An Economic Theory of Clubs. Economica, 32: 1-14.

Bian, Y. 2001. Guanxi capital and social eating: Theoretical models and empirical analyses. In N. Lin, R. S. Burt, \& K. Cook (Eds.). Social capital: Theory and research: 275-295. New York: Gruyter.

Bourdieu, P. 1986. The forms of capital. In J. Richardson (Ed.). Handbook of theory and research for the sociology of education: 241-258. New York: Greenwood.

Bowles, S., \& Gintis, H. 2002. Homo reciprocans. Nature, 415: 125-128.

Brennan, R., \& Wilson, J. 2010. Doing business in China: Is the importance of guanxi diminishing? European Business Review, 22(6): 652-665.

Burt, R. S. 1995. Structural holes: The social structure of competition. Cambridge, MA: Harvard University Press.

Burt, R. S. 1997. The contingent value of social capital. Administrative Science Quarterly, 42(2): 339-365. 
Burt, R. S. 2000. The network structure of social capital. Research in Organizational Behavior, 22: 345-423.

Castells, M. 2001. The internet galaxy. Society (Vol. 67). Oxford: Oxford University Press.

Chen, M. 2002. Transcending paradox: The Chinese "middle way" perspective. Asia Pacific Journal of Management, 19: 179-199.

Chen, C., Chen, X., \& Huang, S. 2013. Chinese guanxi: an integrative review and new directions for future research. Management and Organization Review 9(1): 167-207.

Chen, M. J., \& Miller, D. 2010. West meets East: Toward an ambicultural approach to management. Academy of Management Perspectives, 24(4): 17-24.

Chen X. -P., \& Chen, C. C. 2004. On the intricacies of the Chinese guanxi: A process model of guanxi development. Asia Pacific Journal of Management, 21(3): 305-324.

Coleman, J. S. 1988. Social capital in the creation of human capital. American Journal of Sociology, 94: 95-120.

Coleman, J. S. 1990. Foundations of social theory. Cambridge, MA: Harvard Business Press.

Davis, H. 1995. Interpreting guanxi: The role of personal connections in a high context transitional economy. In H. Davies. (Ed.). China business: Context and issues: 155-169. Hong Kong: Longman.

De Graaf, N., \& Flap, H. 1988. "With a little help from my friends": Social resources as an explanation of occupational status and income in West Germany, the Netherlands, and the United States. Social Forces, 67(3): 452-472.

Dowling, P. J., \& Donnelly, N. 2013. Managing people in global markets: The Asia Pacific perspective. Journal of World Business, 48(2): 171-174.

Dunbar, R.I.M. 2014. The social brain, Psychological underpinnings and implications for the structure of organizations. Current Directions in Psychological Science, 23(12): 109114.

Dunning, J. H., \& Kim, C. 2007. The cultural roots of guanxi: An exploratory study. The World Economy, 30(2): 329-341.

Durkheim, E. 1933. The division of labor in society. New York: The Free Press.

Faist, T. 2000. The volume and dynamics of international migration and transnational social spaces. Oxford: Oxford University Press.

Falk, A., \& Fischbacher, U. 2000. A theory of reciprocity. Institute for Empirical Research in Economics Working Paper No. 6. Zurich: University of Zurich.

Fan, Y. 2002a. Guanxi's consequences: Personal gains at social cost. Journal of Business Ethics, 38(4): 371-380.

Fan, Y. 2002b. Questioning guanxi: Definition, classification and implications. International Business Review, 11(5): 543-561.

Fang, T. 2003. A critique of Hofstede's fifth national culture dimension. International Journal of Cross Cultural Management, 3(3): 347-368.

Fang, T. 2012. Yin yang: A new perspective on culture. Management and Organization Review, 8(1): 25-50.

Farh, J. -L., Earley, P. C., \& Lin, S. -C. 1997. Impetus for action: A cultural analysis of justice and organizational citizenship behavior in Chinese society. Administrative Science Quarterly, 42: 421-444.

Faure, G. O., \& Fang, T. 2008. Changing Chinese values: Keeping up with paradoxes. International Business Review, 17(2): 194-207.

Fehr, E., \& Falk, A. 1999. Wage rigidity in a competitive incomplete contract market. Journal of Political Economy, 107(1): 106-134.

Fukuyama, F. 1995. Trust: The social virtues and the creation of prosperity. New York: The Free Press. 
Fukuyama, F. 2002. Social capital and development: The coming agenda. SAIS Review, XXII(1): 23-37.

Gilbert, D. 2003. Strategic decision-making in Japaese trading companies: Case studies of information search activities. Journal of the Australian and New Zealand Academy of Management, 9(1): 27-42.

Granovetter, M. 1985. Economic action and social structure: The problem of embeddedness. American Journal of Sociology, 91(3): 481-510.

Granovetter, M. 1995. Getting a job: A study of contacts and careers. Chicago: Chicago University Press.

Granovetter, M. S. 1973. The strength of weak ties. American Journal of Sociology, 78(6): 1360-1380.

Greif, A. 1989. Reputation and coalitions in medieval trade: Evidence on the Maghribi traders. Journal of Economic History, 49(4): 857-882.

Greif, A. 2006. Institutions and the Path to the Modern economy. Lessons from Medieval Trade. Cambridge: Cambridge University Press.

Gu, F. F., Hung, K., \& Tse, D. K. 2008. When does guanxi matter? Issues of capitalization and its dark sides. Journal of Marketing, 72(4): 12-28.

Guthrie, D. 1998. The declining significance of guanxi in China's economic transition. The China Quarterly, 154(1): 254-282.

Halpern, D. 2005. Social capital. Cambridge, UK: Polity.

Hennart, J.-F. 2015. Leveraging Asian institutions to deepen theory: a transaction cost perspective on relational governance. Asian Business \& Management, 14(4): forthcoming.

Hofstede, G. 2007. Asian management in the 21st century. Asia Pacific Journal of Management, 24(4): 411-420.

Horak, S. 2014. Antecedents and characteristics of informal relation-based networks in Korea: Yongo, yonjul and inmaek. Asia Pacific Business Review, 20(1): 78-108.

House, R. J., Hanges, P. J., Javidan, M., Dorfman, P. W., \& Gupta, V. 2004. Culture, leadership, and organizations: The globe study of 62 societies. Thousand Oaks: Sage.

Huang, X. 2008. Guanxi networks and job searches in China's emerging labour market: A qualitative investigation. Work, Employment \& Society, 22(3): 467-484.

Hutchings, K., \& Weir, D. 2006. Understanding networking in China and the Arab world: Lessons for international managers. Journal of European Industrial Training, 30(4): 272-290.

Jones, C., Hesterly, W., \& Borgatti, S. 1997. A general theory of network governance: Exchange conditions and social mechanisms. Academy of Management Review, 22(4): 911-945.

Kahneman, D., Knetsch, J. L., Thaler, R., \& Kahneman, B. D. 1986. Fairness as a constraint on profit seeking: Entitlements in the market. American Economic Review, 76(4): 728741.

Kim, Y.-H. 2000. Emergence of the network society: Trends, new challenges, and an implication for network capitalism. Korea Journal, 40(3): 161-184.

Lee, D. J., Pae, J. H., \& Wong Y. H. 2001. A model of close business relationships in China (guanxi). European Journal of Marketing, 35(1/2): 51-69.

Lee, J. 2000. Society in a vortex? Yonjul network and civil society in Korea. Korea Journal, 40(1): 366-391.

Lee, K. - Y. 2007. Kulturelle Inkompatibilität von Kyopos und südkoreanischen Unternehmen in Deutschland Kyopos in Deutschland. In D. Wagner \& B.-F. Voigt (Eds.). Diversitymanagement als leitbild von personalpolitik: 315-341. Wiesbaden: DUV Gabler. 
Lew, S. C. 2013. Missing links in understanding Korean development. In S. C. Lew (Ed.). The Korean economic development path - Confucian tradition, affective network: 3-24. New York: Palgrave Macmillan.

Lew, S. -C., Choi, W. -Y., \& Wang, H. S. 2011. Confucian ethics and the spirit of capitalism in Korea: The significance of filial piety. Journal of East Asian Studies, 11(2): 171-196.

Li, P. P. 1998. Towards a geocentric framework of organizational form: A holistic, dynamic and paradoxical approach. Organization Studies, 19(5): 829-861.

Li, P. P. 2007a. Guanxi as the Chinese norm for personalized social capital: Toward an integrated duality framework of informal exchange. In H. W. Yeoung (Ed.). Handbook of research on Asian business: 62-83. Cheltenham, UK: Edward Elgar.

Li, P. P. 2007b. Social tie, social capital, and social behavior: Toward an integrative model of informal exchange. Asia Pacific Journal of Management, 24(2): 227-246.

Li, P. P. 2008. Toward a geocentric framework of trust: An application to organizational trust. Management and Organization Review, 4(3): 413-439.

Li, P. P. 2010. Toward a learning-based view of internationalization: The accelerated trajectories of cross-border learning for latecomers. Journal of International Management, 16(1): 43-59.

Li, P. P. 2012a. The second great encounter in the new era of globalisation: Why and how should the West meet the East? Journal of Trust Research, 2(1): 1-5.

Li, P. P. 2012b. Toward an integrative framework of indigenous research: The geocentric implications of yin-yang balance. Asia Pacific Journal of Management, 29(4): 849-872.

Liang, S. M. 1949. Foundations of Chinese culture. Beijing: Sanlian Press.

Lin, N. 1999. Building a network theory of social capital. Connections, 22(1): 28-51.

Lin, N. 2001. Guanxi: A conceptual analysis. In A. Y. So, N. Lin, \& D. Poston (Eds.). The Chinese triangle of mainland China, Taiwan, and Hong Kong: Comparative institutional analyses: 154-167. Westport: Greenwood.

Lin, N. 2002. How the East and the West shall meet. Development and Society, 31(2): 211244.

Luo, Y. (Ed.). 2000. Guanxi and business. Singapore: World Scientific Publishing Company.

Luo, J. -D., \& Yeh, Y. -C. 2012. Neither collectivism nor individualism: Trust in the Chinese guanxi circle. Journal of Trust Research, 2(1): 53-70.

Macneil, I. 1974. The many futures of contract. California Law Review, 47: 691-816.

Macneil, I. 1978. Contractual adjustments of long-term relations under classical, neoclassical, and relational contract law. Northwestern University Law Review, 72(6): 854-905.

Marsden, P., \& Gorman, E. (2001). Social networks, job changes and recruitment. In I. Berg \& A. Kalleberg (Eds.). Sourcebook of labour markets: 467-502. New York: Springer.

Montgomery, J. 1991. Social networks and labor market outcomes: Toward an economic analysis. The American Economic Review, 81(5), 1408-1418.

Nee, V. 1998. Norms and networks in economic and organizational performance. American Economic Review, 88(2): 85-89. doi:10.1126/science.151.3712.867-a

North, D. C. 1990. Institutions, institutional change and economic performance. Cambridge: Cambridge University Press.

Ostrom, E., \& Ahn, T. K. 2003. Foundations of social capital. Cheltenham, UK: Edward Elgar.

Park, C. -M., \& Shin, D. C. 2005. Social capital and democratic citizenship: The case of South Korea. Japanese Journal of Political Science, 6(1): 63-85.

Peng, M. W., Pinkham, B., Sun, S. L., \& Chen, H. 2009. The institution-based view as a third leg for a strategy tripod. Academy of Management Perspectives, 23(4): 63-81. 
Peng, M. W., Wang, D. Y. L., \& Jiang, Y. 2008. An institution-based view of international business strategy: A focus on emerging economies. Journal of International Business Studies, 39(5): 920-936.

Portes, A. 1998. Social capital: Its origins and applications in modern sociology. Annual Review of Sociology, 24: 1-24.

Przeworski, A., \& Teune, H. 1970. The logic of comparative social inquiry. New York: John Wiley \& Sons.

Putnam, R. D. 1995. Bowling alone: America's declining social capital. Journal of Democracy, 6(1): 65-78.

Putnam, R. D., Leonardi, R., \& Nanetti, R. Y. 1993. Making democracy work: Civic traditions in modern Italy. Princeton, New Jersey: Princeton University Press.

Pye, L. 1982. Chinese commercial negotiating style. Santa Monica: Rand.

Sandler, T., \& Tschirhart, J. 1997. Club theory: Thirty years later. Public Choice, 93: 335355.

Scott, R. W. 2010. Reflections: The past and future of research on institutions and institutional change. Journal of Change Management, 10(1): 5-21.

Sik, S. H. 2005. A brief history of Korea. The spirit of Korean cultural roots. Seoul: Ewha Womens University Press.

Song, F., Cadsby, C. B., \& Bi, Y. 2012. Trust, reciprocity, and guanxi in China: An experimental investigation. Management and Organization Review, 8(2): 397-421.

Sugden, R. 1984. Reciprocity: The supply of public goods through voluntary contributions. Economic Journal, 94(376): 772-787.

Suzuki, N. 1989. The attributes of Japanese CEOs" Can theu be trained? Journal of Management Development, 8(4): 5-11.

Taube, M. 2013. Relational corruption in the PR China: institutional foundations and its (dys)-functionality for economic development and growth, Zeitschrift fur Vergleichende Politikwissenschaft, 7 (supplement 1): 89-116.

Weber, M. 1951. The religion of China. New York: Free Press.

Williamson, O. E. (1996). The mechanisms of governance. New York: Oxford University Press.

Williamson, O. 1979. Transaction-cost economics: the governance of contractual relations. Journal of Law and Economics, 22(2): 233-261.

Wilson, J., \& Brennan, R. 2010. Doing business in China: Is the importance of guanxi diminishing? European Business Review, 22(6): 652-665.

Woolcock, M. 1998. Social capital and economic development: Toward a theoretical synthesis and policy framework. Theory and Society, 27(2): 151-208.

Xin, K. R. K., \& Pearce, J. L. 1996. Guanxi: Connections as substitutes for formal institutional support. Academy of Management Journal, 39(6): 1641-1658.

Yamagishi, T., Jin, N., \& Kiyonari, T. 1999. Bounded generalized reciprocity: Ingroup favoritism and ingroup boasting. Advances in Group Processes, 16: 161-197.

Yang, M. M.-H. 1994. Gifts, favors, and banquets: The art of social relationships in China. New York: Cornell University Press.

Yee, J. 2000a. The social networks of Koreans. Korea Journal, 40(1): 325-352.

Yee, J. 2000b. Too modern too soon? Dualism in civil society, everyday life, and social relations in contemporary Korea. Korea Journal, 40(1): 282-284.

Yee, J., \& Chang, D. 2009: Transparency, a key factor to improve social cohesion: A review of the Korean experience in the context of social quality research. Development and Society, 38(2): 259-275.

Yee, J. 2015. Social capital in Korea: Relational capital, trust, and transparency. International Journal of Japanese Sociology, 24(1): 30-47. 
Yi, L. M., \& Ellis, P. 2000. Insider-outsider perspectives of guanxi. Business Horizons, 43(1): $25-30$.

Zhang, J., \& Pimpa, N. 2010. Embracing guanxi. International Journal of Asian Business and Information Management, 1(1): 23-31.

\section{Figures and Tables}

Figure 1: Selected structural antecedents of informal social networks

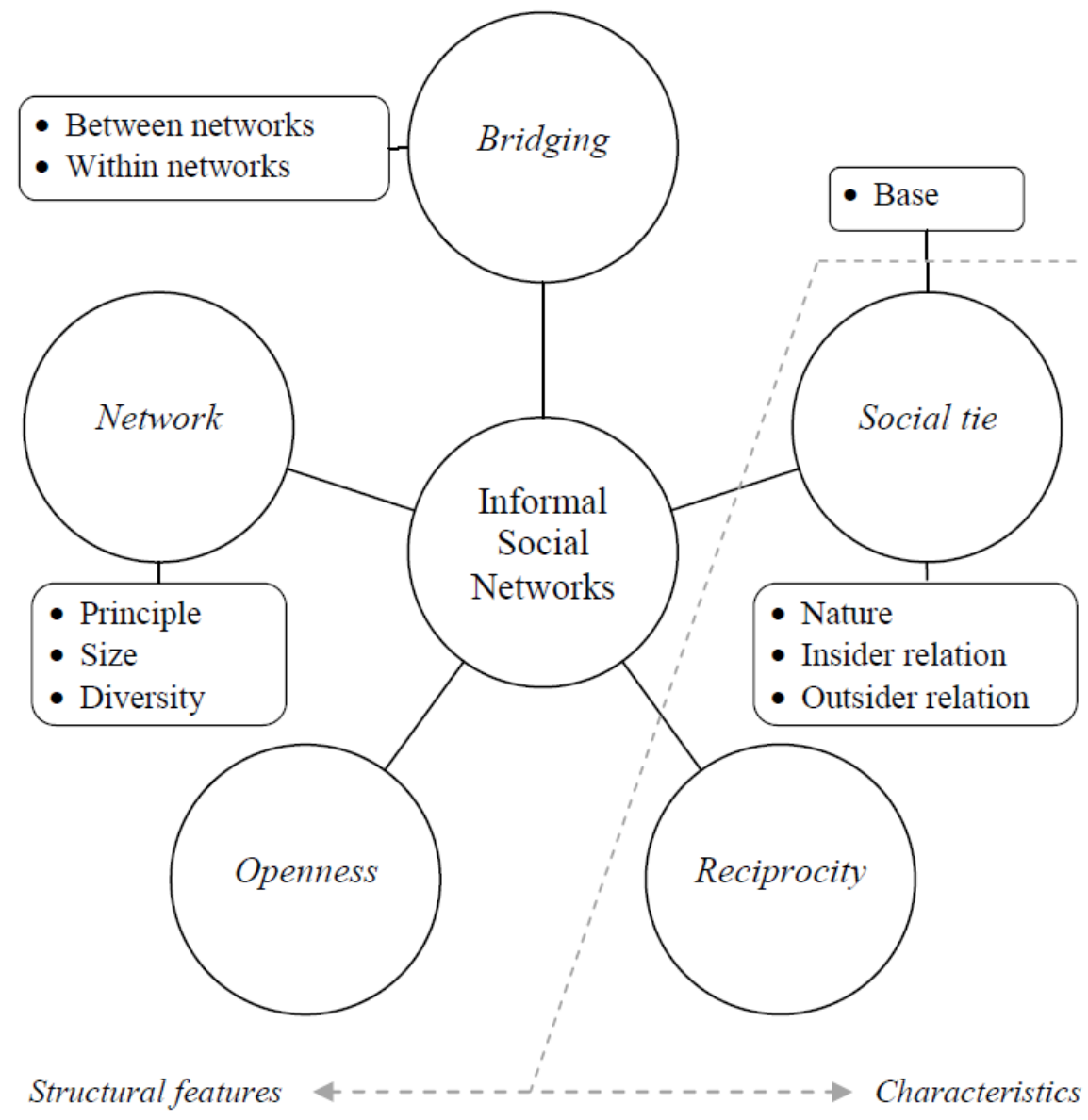


Table 1: Comparison of the characteristics of Guanxi versus Yongo

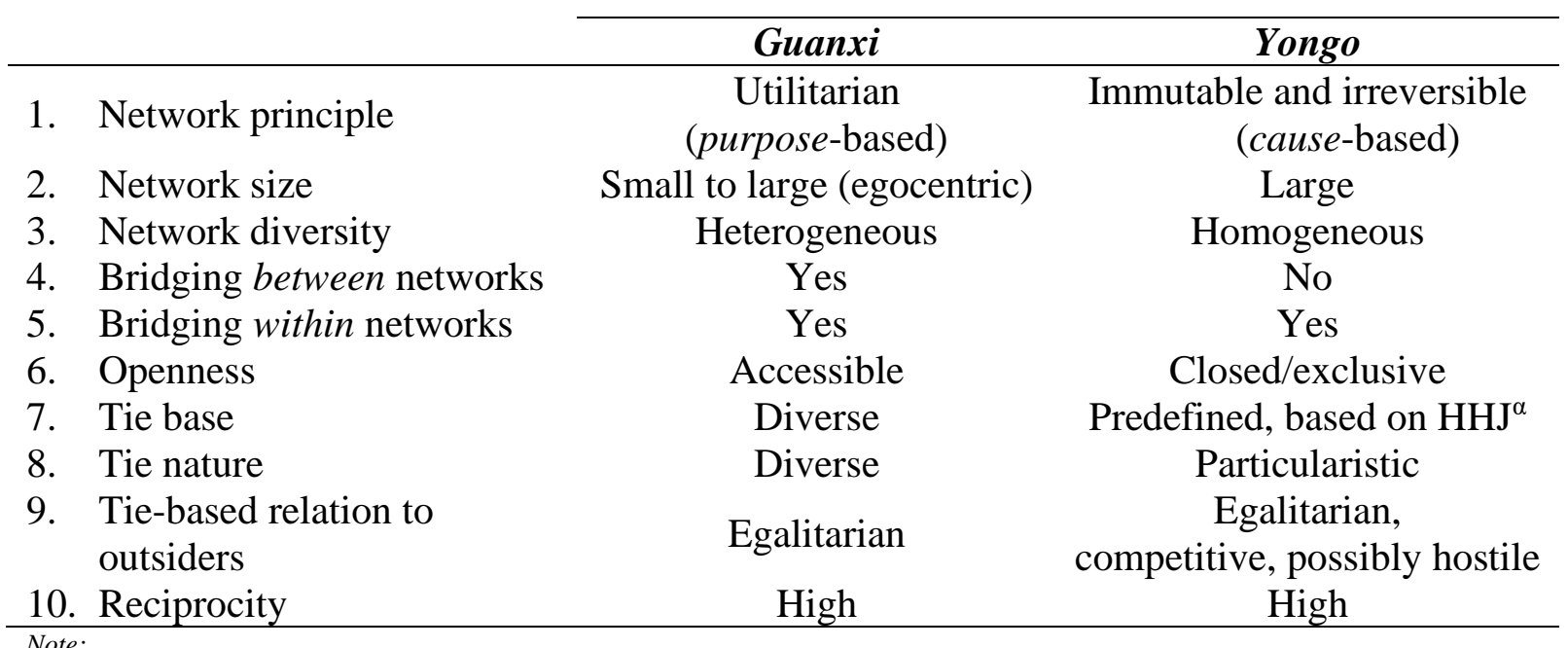

${ }^{\alpha}$ HHJ: Hakyon (education-based ties), hyulyon (family or blood ties), and jiyon (regional/origin-based ties). 
Table 2: Stylized illustration of differences in transactions conducted by Guanxi and Yongo networks

\begin{tabular}{ll}
\hline Situation (example) & $\begin{array}{l}\text { Guanxi- versus Yongo-based transactions linked to } \\
\text { network principles (cf. Table 1) }\end{array}$ \\
\hline
\end{tabular}

A works in company $\mathrm{X}$ and is connected via an informal social network to $\mathrm{B}$ in company $\mathrm{Z}$.
Based on network principle (1):

(i) Given the utilitarian (purpose-based) structure of Guanxi networks, the relationship between A and B is either still weak and entails only a low level of trust if the connection has not gone through a significant number of affirmative reciprocal transactions, or is strong and based on high trust levels if $\mathrm{A}$ and $\mathrm{B}$ share a long history of successful reciprocal exchanges.

(ii) In a Yongo network, A and B will interact at a comparatively high level of reciprocal trust largely irrespective of their transaction history.

$B$ requires help to reciprocate/respond to a request for help from $\mathrm{C}$, one of his/her closest (network) partners. the network is determined by the size (2) and heterogeneity (3) of B's network. Guanxi networks may differ in size, but
The chance of B identifying a resourceful third party within are usually highly heterogeneous in their membership. Yongo networks in comparison are large in size, but highly homogeneous. In a Guanxi environment, but not a Yongo environment, B may also contact external actors to establish a bridge to other networks and access the required resources in this way.

B identifies $\mathrm{A}$ as possessing the required resources and approaches $\mathrm{A}$ to ask a favor benefitting $\mathrm{C}$, who works for company $\mathrm{Z}$ and does not know A personally.

In both Guanxi and Yongo networks, intra-network bridging is possible (5). However, given the cause-based network principle (1) of Yongo networks, the pressure to engage is particularly strong for A in a Yongo context. In a Guanxi context, A has greater leeway to excuse him/herself from providing the service, especially if the transaction history with B is short and trust levels are low. B may then also resort to mobilizing equivalent services by means of establishing a bridge between networks (4), something that is not possible for Yongo networks.

A provides the service to $\mathrm{C}$ at the In both Guanxi and Yongo networks, A can now expect to request of $\mathrm{B}$. receive a reciprocal favor (10) from $\mathrm{B}$ and/or $\mathrm{C}$.

A reflects on his/her relationship with $\mathrm{B}$ and $\mathrm{C}$ and wishes to invite $\mathrm{D}$ into their network.
The network openness (6) required to allow outsiders access to an existing network is present in a Guanxi context, but is alien to Yongo structures. With their predefined tie base (7), in which network membership is a non-negotiable natural attribute, the nature of ties (8) in the network is highly particularistic, and relations to outsiders (9) are characterized by mistrust and hostility, Yongo networks lack the structural pre-disposition to integrate new members from external environments. In contrast, Guanxi networks can build on multi-facetted tie bases (7), different manifestations of the nature of specific ties (8), and an egalitarian approach to outsiders (9), who are from the outset understood to be potential network members. As such, Guanxi networks are open to new members from the outside (6). 


\section{DuEPublico}

\section{Duisburg-Essen Publications online}

offen im Denken

\section{$\mathbf{U b} \mid \begin{aligned} & \text { universitäts } \\ & \text { bibliothek }\end{aligned}$}

This text is made available via DuEPublico, the institutional repository of the University of Duisburg-Essen. This version may eventually differ from another version distributed by a commercial publisher.

DOI: $\quad 10.1007 / \mathrm{s} 10490-015-9452-\mathrm{x}$

URN: urn:nbn:de:hbz:464-20200205-162130-9

This is a post-peer-review, pre-copyedit version of an article published in Asia Pacific Journal of Management, 33(3), 595-616 (2016).

All rights reserved. 